\title{
Spindle Cell Hemangioma of the Nasal Cavity: A Rare Tumor with Unusual Presentation
}

\author{
Vijayalaxmi Suranagi, Anil S Harugop, Hema B Bannur, Ganga S Pilli, RS Mudhol
}

\begin{abstract}
Vascular tumors as such are rare in the nasal cavity. Few cases of lobular capillary hemangioma, cavernous hemangioma and epitheloid hemangioendothelioma have been reported in the nasal cavity. But, there are no reports of spindle cell hemangioma occurring within the nasal cavity. They usually present as subcutaneous nodules in the extremities. A case of recurrent bleeding polypoid lesion in the left nasal cavity, arising from the middle turbinate which showed features of spindle cell hemangioma is reported for its rarity and unusual presentation. The tumor was excised by minimally invasive transnasal endoscopic approach.
\end{abstract}

Keywords: Spindle cell hemangioma, Transnasal endoscopy, Middle turbinate, Nasal cavity, Bleeding polyp.

How to cite this article: Suranagi V, Harugop AS, Bannur HB, Pilli GS, Mudhol RS. Spindle Cell Hemangioma of the Nasal Cavity: A Rare Tumor with Unusual Presentation. Clin Rhinol An Int J 2013;6(3):149-151.

Source of support: Nil

Conflict of interest: None declared

\section{INTRODUCTION}

Spindle cell hemangioma $(\mathrm{SCH})$ is a rare vascular tumor, usually presenting as subcutaneous nodules in the extremities. Spindle cell hemangioma occurring in the head and neck region is extremely rare. Very few cases of SCH have been reported in the soft tissue of head and neck, oral cavity and in the temporal muscle. ${ }^{1-3}$ Extensive literature search did not reveal any case of $\mathrm{SCH}$ occurring in the nasal cavity, reported till now. It is important to recognize these lesions, since they have high rate of recurrence, and metastatic potential of the tumor is still debatable.

\section{CASE REPORT}

A 27 years old female presented with history of left nasal mass since 15 days. The mass was progressively increasing in size, associated with nasal pain and bleeding from the left nasal cavity.

On examination, a reddish mass was seen protruding from the left nasal cavity, soft to firm in consistency, bleeding on touch and tender. The mass was nonreducible and probe could be passed all around the mass (Fig. 1). Magnetic resonance imaging (MRI) scan was done which revealed a soft tissue mass occupying the left nasal cavity, radioenhancing without evidence of bony destruction or paranasal sinus involvement (Fig. 2A).
Transnasal endoscopic technique was used to excise the mass. During endoscopy, it was found that the mass was polypoid, originated from the anterior end of middle turbinate and measured $7 \times 3 \mathrm{~cm}$. Excision was associated with moderate amount of bleeding, and the patient was compliant during the procedure. The mass was sent to the surgical pathology department for diagnosis.

\section{Gross}

The mass was polypoid, gray-brown and blackish at the the externally protruding end. Cut surface showed brownish congested and hemorrhagic areas.

\section{Microscopy}

Multiple cavernous vascular spaces of varying calibre, lined by endothelial cells, engorged with blood some containing thrombi were present. Between these were seen, slit-like spaces, bland spindle cells and round epitheloid cells containing intracytoplasmic lumina. No cellular atypia or mitotic activity was noted (Figs 2B to D). A diagnosis of spindle cell hemangioma was given.

The patient returned after 2 months with a small nodular lesion in the same area. The microscopic picture was similar to the previous lesion.

\section{DISCUSSION}

Spindle cell hemangioma, previously known as spindlecell hemangioendothelioma, was first described by Sharon Weiss and Enzinger (1986), as low grade angiosarcoma. Later in 1996, they were reclassified as spindle cell hemangioma. ${ }^{4,5}$ They usually affect subcutis of the distal

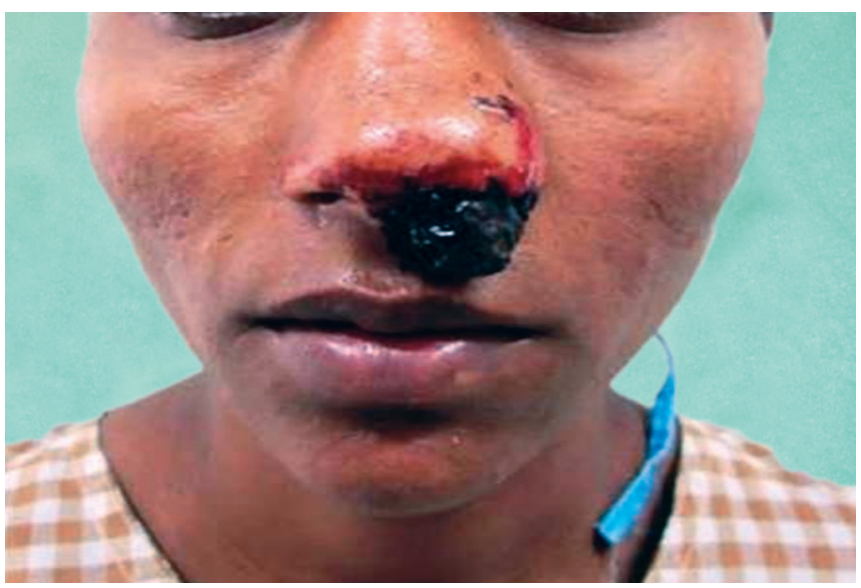

Fig. 1: Tender reddish mass protruding from the left nasal cavity 


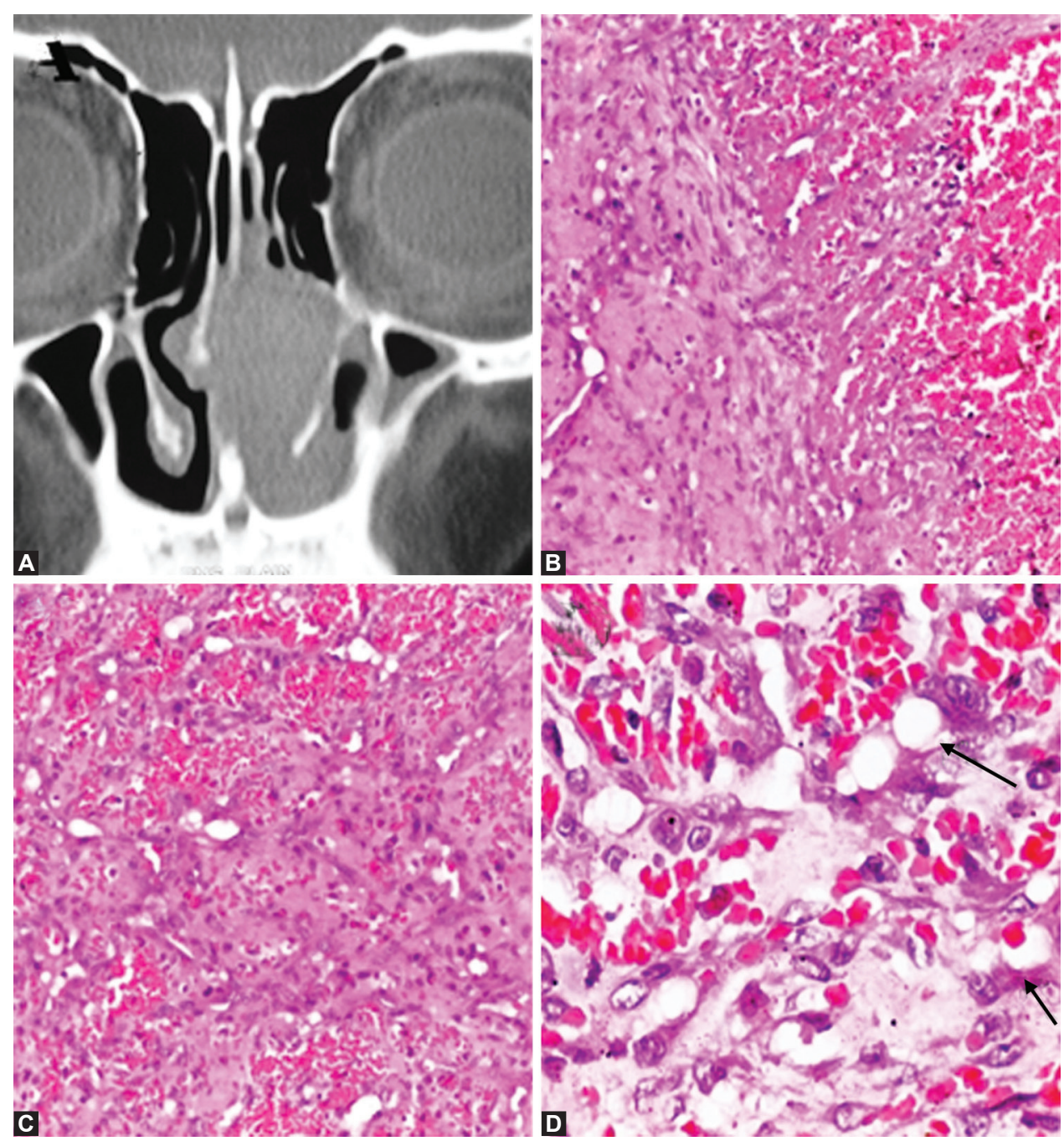

Figs 2A to D: (A) Computer tomography scan revealing soft tissue mass in left nasal cavity, ( $B$ and $C$ ) cavernous vascular spaces engorged with blood, bland spindle cells in intervening stoma, (D) round epitheloid endothelial cells with intracytoplasmic lumina (arrow)

extremities, and have benign indolent course. Approximately $50 \%$ of the cases are intravascular. ${ }^{5}$ As per our knowledge, only 10 cases of $\mathrm{SCH}$ have been reported in the head and neck region, six in the soft tissue and lip, three in the oral cavity and one in the temporal muscle. ${ }^{1-3}$ Till date, no case of $\mathrm{SCH}$ occurring in the nasal cavity or middle turbinate has been reported.

There has been a considerable debate regarding the pathogenesis of this tumor. The lesions arise in the vicinity of abnormal vessels, supporting the idea that the spindle cell hemangioma is most likely a vascular malformation in which variation in blood flow gives rise to alternating areas of vascular expansion and collapse. Spindle cell hemangioma has been associated with Maffucci's syndrome, Klippel-Trenaunay syndrome, and lymphedema, all of which may contribute to a compromise in a blood flow to the area. ${ }^{5}$ An immunohistochemical and flow cytometric study on six cases of SCH by Fukunaga et $\mathrm{al}^{6}$ revealed that there was no significant correlation among DNA ploidy,
S-phase fraction and local recurrence in SCH. It was also observed that factor-VIII related antigen, CD34, vimentin and lectin binding Ulex europaeus agglutinin 1 stained endothelial cells lining vascular channels and vacuolated, or epithelioid cells. Spindle cells in the solid areas were negative for these endothelial markers except for vimentin but showed divergent positive immunoreactions of HHF35, alpha-smooth muscle actin, desmin and collagen type IV.

Perkins et $\mathrm{al}^{7}$ who studied 78 cases of SCH to reevaluate the pathogenesis and determine their long-term behavior. They found that despite conservative excisions in most patients, prognosis was excellent. Fifty-eight percent developed recurrences, but none developed metastasis or died of the direct effects of the tumor. They recommended the use of spindle cell hemangioma for solitary lesions and spindle cell hemangiomatosis for multifocal lesions. They believed that recurrences represented contiguous spread along or multifocal involvement of a vessel. However, this is the only study available in the literature with long-term 
follow-up of large number of patients. Some more similar studies are required to confirm the biological behavior or the metastatic potential of the tumor.

Spindle cell hemangioma can be confused with Kaposi's sarcoma. The presence of cavernous vessels and epithelioid endothelial cells (which are not seen in Kaposi's sarcoma) are the most reliable features for distinguishing the two tumors. Recurrence rate of the tumor is as high as $60 \%{ }^{5}$ Hence, close follow-up of the patient is essential.

\section{CONCLUSION}

The present case is a $\mathrm{SCH}$ arising from the middle turbinate mucosa in the left nasal cavity. The unique features of this case are extremely rare site of occurrence, and successful complete excision of the lesion with minimally invasive transnasal endoscopic technique and recurrence within 2 months which could be managed successfully using endoscopic approach.

\section{REFERENCES}

1. Tosios KI, Gouveris I, Sklavounou A, Koutlas IG. Spindle cell hemangioma (hemangioendothelioma) of the head and neck: case report of an unusual (or underdiagnosed) tumor. Oral Surg Oral Med Oral Pathol Oral Radiol Endod 2008;105(2):216-221.

2. Sheehan M, Roumpf SO, Summerlin DJ, Billings SD. Spindle cell hemangioma: report of a case presenting in the oral cavity. J Cutan Pathol 2007 Oct;34(10):797-800.

3. Minagawa T, Yamao T, Shioya R. Spindle cell hemangioendothelioma of the temporal muscle resected with zygomatic osteotomy: a case report of an unusual intramuscular lesion mimicking sarcoma. Case Rep Surg 2011;481654. Epub 2011 Sep 6.

4. Weiss SW. Spindle cell hemangioendothelioma: a low-grade angiosarcoma resembling a cavernous hemangioma and
Kaposi's sarcoma. American Journal of Surgical Pathology 1986;10(8):521.

5. Benign tumours and tumour-like lesions of blood vessels. Enzinger and Weiss's Soft tissue tumors. 4th ed. 2001;853-854.

6. Fukunaga M, Ushigome S, Nikaido T, Ishikawa E, Nakamori K. Spindle cell hemangioendothelioma: an immunohistochemical and flow cytometric study of six cases. Pathol Int 1995 Aug; 45(8):589-595.

7. Perkins P, Weiss SW. Spindle cell hemangioendothelioma. An analysis of 78 cases with reassessment of its pathogenesis and biologic behavior. Am J Surg Pathol 1996 Oct;20(10): 1196-1204.

\section{ABOUT THE AUTHORS}

\section{Vijayalaxmi Suranagi (Corresponding Author)}

Professor, Department of Pathology, Jawaharlal Nehru Medical College, Belgaum, Karnataka, India, Phone: 9964318734, e-mail: madhudhori@rediffmail.com

\section{Anil S Harugop}

Professor, Department of ENT, Jawaharlal Nehru Medical College Belgaum, Karnataka, India

\section{Hema B Bannur}

Professor, Department of Pathology, Jawaharlal Nehru Medical College, Belgaum, Karnataka, India

\section{Ganga S Pilli}

Professor and Head, Department of Pathology, Jawaharlal Nehru Medical College, Belgaum, Karnataka, India

\section{RS Mudhol}

Professor, Department of ENT, Jawaharlal Nehru Medical College Belgaum, Karnataka, India 